\title{
Lingüística
}

Vol. 36-2, diciembre 2020: 9-29

ISSN 2079-312X en línea

DOI: $10.5935 / 2079-312 X .20200012$

\section{O IMPACTO DE O AMIGO DA ONÇA EM CHARGES CONTEMPORÂNEAS: ETHOS E HUMOR}

\author{
EL IMPACTO DE O AMIGO DA ONÇA EN HISTORIETAS POLÍTICAS \\ CONTEMPORÁNEAS: ETHOS Y HUMOR
}

THE IMPACT OF THE O AMIGO DA ONÇA IN CONTEMPORANEOUS CHARGES: ETHOS AND HUMOR

\author{
Ana Cristina Carmelino \\ Universidade Federal de São Paulo \\ anacriscarmelino@gmail.com \\ 0000-0002-7576-0595 \\ Paulo Ramos \\ Universidade Federal de São Paulo \\ contatopauloramos@gmail.com \\ 0000-0002-9348-4176
}

\section{Resumo}

Este artigo evidencia a longevidade de O Amigo da Onça, personagem do humor gráfico brasileiro criado por Péricles Maranhão.

Publicada na revista O Cruzeiro, de 1943 a 1972, a história em quadrinhos o mostrava colocando outros em situações embaraçosas. A hipótese a ser trabalhada é a de que o ethos de pouco confiável dele é associado a outras pessoas de modo a produzir humor e criticar, o que contribui para perpetuar 0 personagem-título. $\mathrm{O}$ exemplo a ser analisado neste texto é o do ex-presidente do Brasil Michel Temer. O objetivo é mostrar, por meio do exame de charges, que a aproximação de Temer a $\mathrm{O}$ Amigo da Onça funciona como técnica de produzir humor, bem como sugere suposições ideológicas sobre a forma de agir do ex-presidente. O estudo se ancora em pressupostos de teorias discursivas, caso do campo do humor e das noções de memória e ethos.

Palavras-chave: charge; ethos; O Amigo da Onça; Michel Temer.

\section{Resumen}

Este artículo demuestra la longevidad de O Amigo da Onca, personaje de humor gráfico brasileño creado por Pericles Maranhão. 
Publicado en la revista O Cruzeiro de 1943 a 1972, la historieta lo mostraba colocando a los demás en situaciones embarazosas. La hipótesis por ser trabajada es la de que el ethos de poco confiable de él se asocia con otras personas para producir humor y criticar lo que contribuye a perpetuar el personaje-título. El ejemplo por ser analizado en este trabajo es el del expresidente de Brasil, Michel Temer. El objetivo es mostrar, por medio de los dibujos que la aproximación de Temer a O Amigo da Onça funciona como técnica para producir humor, y sugiere suposiciones ideológicas sobre la forma de actuar del ex Presidente. El estudio se basa en los presupuestos de las teorías discursivas, como es el caso del campo del humor y las nociones de memoria y ethos.

Palabras-clave: historieta política; ethos; O Amigo da Onca; Michel Temer.

\begin{abstract}
This article shows the longevity of $O$ Amigo da Onça, a Brazilian humor character created by Péricles Maranhão.

Published in the O Cruzeiro magazine, from 1943 to 1972, the comic showed him putting others in embarrassing situations. The hypothesis to be worked out is that his unreliable ethos is associated with other people to produce humor and criticize, which contributes to perpetuate the character. The example in this text to be analyzed is the Brazilian ex-president Michel Temer. The objective is to show, through the charges examination, that Temer's approach to O Amigo da Onça acts as a technique to produce humor, as well suggests ideological assumptions about the former president's way of acting. The study is anchored in assumptions of discursive theories, in the case of the field of humor and of the notions of memory and ethos.
\end{abstract}

Keywords: charge; ethos; O Amigo da Onça; Michel Temer.

Recebido: $31 / 01 / 2019$

Aceito: 25/03/2019

\title{
1. Considerações iniciais: charge, humor e memória
}

Áreas dos estudos da linguagem, em particular as de cunho discursivo e textual, têm enfrentado o desafio de trazer respostas para analisar (e explicar) fenômenos envolvendo as imagens. A questão que se coloca é como abordar tais produções, mantendo como foco o escopo linguístico. Embora se tenha ciência de que muito ainda há a ser trilhado nessa estrada, pode-se observar que uma tendência seja a de observar enunciados verbo-visuais (ou multimodais) sob o prisma de teorias já consolidadas no campo linguístico. 
É nesse contexto que se insere este artigo, que se vale principalmente de premissas discursivas para a abordagem de trabalhos que mesclam imagem e palavra.

Pretende-se refletir sobre a longevidade da memória discursiva de 0 Amigo da Onça em trabalhos do humor gráfico brasileiro contemporâneo. Ele é tido como um dos mais importantes da imprensa e das histórias em quadrinhos do país. Criado pelo desenhista Péricles de Andrade Maranhão (1924-1961), circulou em O Cruzeiro (1928-1983) durante quatro décadas (de 1943 a 1972) ${ }^{1}$. De tão famosa que era sua presença na revista semanal, continuou a ter histórias criadas mesmo após a morte de seu idealizador.

É difícil precisar o que o tornou tão aceito pelos leitores da revista, uma das mais importantes do Brasil no século passado. Fato é que caiu nas graças do público, a ponto de ajudar na popularização da expressão que dá nome a ele, já dicionarizada, inclusive. Dizer que alguém é amigo da onça é atribuir ao outro a característica de ser "falso, hipócrita, infiel" (Ferreira 1999: 122). É justamente o que se lê em suas histórias.

Produzidas sempre em uma cena só, no tamanho de uma página, elas mostram O Amigo da Onça colocando outros em situações difíceis e constrangedoras. Tal conduta constrói para ele o ethos (a representação) de "sacana"" (cf. Carmelino 2017). As narrativas apresentam um tipo de humor cotidiano, que ressalta costumes típicos, refletindo, portanto, questões do dia a dia da sociedade à época em que foram criadas: reiteram certos comportamentos, criticam ou desvelam maneiras de ser.

Observa-se que, em produções contemporâneas de humor gráfico, o ethos de O Amigo da Onça é recuperado, muitas vezes sendo associado a políticos brasileiros. A proposta é analisar alguns desses trabalhos, com particular interesse em charges, gênero que se ancora em fatos do noticiário para fazer deles uma leitura tendencialmente cômica e crítica. A hipótese a ser trabalhada é a de que o ethos de pouco confiável do personagem é associado a outras pessoas, de modo a produzir humor e criticar, o que contribui para perpetuar a criação do personagem-título. Nesse sentido, parte-se do pressuposto de que existe uma memória discursiva de $O$ Amigo da Onça resgatada em tais trabalhos, retomada tanto verbalmente (linguisticamente, portanto) quanto visualmente (sendo, aqui, recuperada por meio das imagens). Desse modo, percebe-se uma materialidade discursiva que permite identificar uma longevidade dele no imaginário de autores e leitores.

O caso a ser destacado neste artigo é o do ex-presidente do Brasil Michel Temer, empossado após o impeachment da titular, Dilma Rousseff, em 31 de agosto de 2016, e cuja gestão finalizou em 31 de dezembro de 2018.

\footnotetext{
${ }^{1}$ Convém salientar que as histórias produzidas por Péricles foram publicadas em $O$ Cruzeiro de 23 de outubro de 1943 a 3 de fevereiro de 1962, pouco após a morte do desenhista (que se suicidou em 31 de dezembro de 1961). A popularidade do personagem fez com que a série tivesse continuidade, passando, desse modo, a ser desenhada por Carlos Estevão e a ser publicada até 1972.

2 A palavra sacana, segundo Ferreira (1999), diz respeito a que ou quem: 1) é libertino, devasso; 2) tem mau-caráter, ludibria ou aufere vantagens que caberiam a outro(s); finório, espertalhão; 3) é brincalhão, de espírito crítico ou trocista, que faz comentários ou brincadeiras divertidos ou perversos, mas com graça, a respeito de seres ou de coisas; gozador.
} 
O objetivo deste texto é mostrar, por meio do exame de charges, que a aproximação de Temer a $\mathrm{O}$ Amigo da Onça funciona não apenas como técnica de produzir humor, mas também como suposições ideológicas da forma de agir de Temer. A análise será feita à luz de alguns pressupostos teóricos da Análise do Discurso, especialmente do conceito de ethos discursivo, e, para entender o texto chárgico, da noção de memória discursiva e de questões ligadas ao campo do humor.

Do ponto de vista da Linguística, especificamente sob a ótica da Análise do Discurso, Possenti (2014) defende a tese de que o humor pode ser considerado um campo ${ }^{3}$. Não se trata de defini-lo, mas de enquadrá-lo numa categoria mais ampla. Seguir essa linha de abordagem significa entender que o humor é fruto de determinadas regras sociais específicas, tem seu universo, suas funções. Compilando algumas possíveis características desse campo, Possenti (2014: 27-39) destaca que:

- é internamente heterogêneo: apresenta diversas teorias, tendências;

- compreende certos gêneros: os estritamente humorísticos e os que se valem eventualmente do humor;

- circula em diferentes espaços; trata de qualquer tema (sexo, instituição, política, questões existenciais, culturais, tipos humanos) e luta para que nenhum controle ou proibição atinja suas produções;

- não pretende ser "pragmático", realista ou eficaz;

- sua produção (que pode ou não ser assinada) depende de uma técnica, que pode estar relacionada a elementos linguísticos ou a fatos referentes ao entorno sociocultural;

- apresenta diferentes tipos de humor (popular, erudito).

Às considerações de Possenti (2014) poderíamos incluir que o humor pode assumir diferentes funções: divertir, denunciar, liberar (romper com 0 proibido), criticar, persuadir, escancarar comportamentos não admitidos pelas normas sociais, refletir sobre práticas socialmente enraizadas na cultura de um povo, sobre modos de ser, sobre representações.

Esclarecidas algumas das formas pelas quais o humor pode ser visto, compreendido ou caracterizado na perspectiva linguística ${ }^{4}$, voltemos a tratar da charge, gênero a ser abordado neste texto. Como uma das produções do humor gráfico (caso também dos cartuns, das caricaturas, das tiras cômicas e de algumas histórias em quadrinhos), as charges geralmente reportam-se a pessoas e a acontecimentos do noticiário, buscando questionar, criticar, denunciar, muito mais do que divertir (Possenti e Carmelino 2016). Na verdade, consistem em um texto opinativo multimodal assinado, que resume situações que a sociedade vive, reinventando-as com recursos gráficos.

${ }^{3}$ O conceito de campo, proposto por Bourdieu (2004) e reformulado por Maingueneau (2005), é caracterizado no interior de um universo discursivo, no qual é possível isolar espaços discursivos que mantêm relação com certos discursos.

${ }^{4}$ Carmelino (2009) busca caracterizar o humor - registre-se, a autora não o define, pois isso, segundo ela, só poderia ser feito sob o olhar de uma abordagem teórica que o toma como objeto de reflexão - como fenômeno complexo, multifacetado e interdisciplinar, presente em diferentes produções (essencialmente ou eventualmente humorísticas) de vários domínios discursivos. O interesse, aqui, é analisar do ângulo linguístico. 
Versam, portanto, sobre objetos reais, mas os recriam de forma ficcional (cf. Teixeira 2005).

Convém registrar ainda que, para interpretar as charges, é preciso recuperar os enunciados e/ou fatos, comumente veiculados pela imprensa, que motivaram sua criação. Sem essas informações, é difícil saber qual o seu tema e esclarecer como o riso é suscitado. Desse modo, se o leitor das charges não dispuser dos dados a que elas aludem, ou seja, se não tiver uma memória de tais informações, não consegue produzir o sentido pretendido. A memória, que desempenha um papel extremamente importante em qualquer realização discursiva, torna-se particularmente especial no que se refere ao texto chárgico.

Na Análise do Discurso, a noção de memória não se refere a lembranças/recordações que um indivíduo tem do que passou, mas a algo coletivo, social: "a estruturação do discursivo vai constituir a materialidade de uma certa memória social" (Pêcheux 1999: 11). Os discursos exprimem uma memória coletiva na qual os sujeitos estão inscritos. Trata-se de acontecimentos exteriores e anteriores ao texto que refletem materialidades que intervêm em sua construção. Conforme destaca Courtine (2009), a função interdiscursiva como domínio da memória permite ao sujeito a retomada (repetição - reprodução/transformação) ou o esquecimento de enunciados.

Pensar a memória dessa maneira é atentar para o fato de que toda produção discursiva que se efetua em certas condições de uma conjuntura movimenta formulações anteriores, já enunciadas. Desse modo, "toda formulação apresenta em seu 'domínio associado' outras formulações que ela repete, refuta, transforma, denega, isto é, em relação às quais ela produz efeitos de memória específicos" (Courtine 2009: 104).

Tratados dos elementos que nos ajudam a entender melhor a construção da charge, passemos à noção de ethos.

\section{O conceito de ethos sob a ótica discursiva}

O debate sobre a noção de ethos, que tem se configurado relevante para os estudos discursivos, não é recente. $\mathrm{Na}$ verdade, perpassa séculos, considerando-se como o termo era visto na Filosofia antiga até a releitura dele, feita nas últimas décadas por diferentes olhares teóricos. Conforme registra Maingueneau (2008a: 11), o "interesse crescente pelo ethos está ligado a uma evolução das condições do exercício da palavra publicamente proferida, particularmente com a pressão das mídias audiovisuais e da publicidade". Embora o percurso expositivo do conceito tenha sido trilhado por muitos dos trabalhos que tratam do tema, achamos importante destacar ao menos as premissas norteadoras dele, antes de expormos como é abordado sob a ótica discursiva.

Partindo de tais dados, é necessário mencionar a Retórica antiga, mais precisamente a de Aristóteles, primeiro filósofo a delinear uma concepção de ethos. Em sua Retórica, o estagirita buscou apresentar uma technè (técnica), cuja finalidade não era apenas examinar o que era persuasivo para certo indivíduo, mas sobretudo para certo tipo de indivíduos. 
A prova pelo ethos, centrada na figura do orador, consiste em causar boa impressão pelo modo como se constrói o discurso, isto é, em dar uma imagem positiva de si (verdadeira ou não) para convencer e persuadir o auditório, ganhando sua confiança. Para dar essa imagem, segundo Aristóteles (Retórica), o orador pode se valer de três qualidades essenciais: a prudência (phronesis), a virtude (aretè) e a benevolência (eunoia).

$\mathrm{Na}$ Análise do Discurso construída na França, Maingueneau foi quem desenvolveu com mais profundidade o conceito de ethos discursivo, afastandoo da noção da retórica clássica e associando-o ao enunciador de um determinado discurso. Para o autor, "todo discurso oral ou escrito supõe um ethos: implica certa representação do corpo de seu responsável, do enunciador que se responsabiliza por ele" (Maingueneau 1998: 60). Amossy (2005), na mesma linha teórica, destaca que a noção de ethos liga-se não apenas à representação que o enunciador faz de si, mas também a que faz dos outros.

Para Maingueneau (2008b), o ethos está vinculado ao exercício da palavra (deixa-se conhecer por índices linguísticos materializados na textualidade), é constitutivo da enunciação e corresponde ao sujeito enunciativo. A esse sujeito (fiador, responsável pelo que enuncia), que profere o discurso em certo tom, atribuem-se um caráter (um conjunto de traços psicológicos) e uma corporalidade (conjunto de traços físicos e indumentários). Maingueneau (2008b: 65) destaca também que o ethos compreende uma forma de "moverse no espaço social (...), apreendida por meio de um comportamento".

Ainda de acordo com os pressupostos de Maingueneau (2008b), não se pode ignorar o fato de que o público constrói representações do ethos do enunciador antes mesmo que ele fale. Essa observação leva o autor a propor uma distinção entre ethos discursivo (efetivo) e ethos pré-discursivo. O ethos discursivo (efetivo) compreende o ethos dito, evocado direta ou indiretamente pelo enunciador a partir de sua própria enunciação, e o ethos mostrado, conformado a partir do conjunto de elementos do quadro da comunicação. 0 ethos pré-discursivo (ou prévio) corresponde à imagem que o público tem do enunciador antes da enunciação, pois, mesmo não conhecendo antecipadamente nada sobre o enunciador, é possível criar expectativas sobre ele, baseando-se em seu posicionamento ideológico ou no gênero discursivo a que o texto pertence.

Com base nessas considerações, Maingueneau (2008b) relaciona a construção da imagem do fiador à noção de estereótipo: o destinatário do discurso se apoiaria em representações sociais cristalizadas, estereótipos, para associar os comportamentos verbais e não verbais do enunciador a um determinado mundo ético, que a enunciação contribui para reforçar ou transformar.

Aproximando os conceitos de ethos e estereótipo, Carmelino e Gatti (2018: 11) defendem a existência de um "ethos-estereotipado", visto especialmente no campo do humor.

Para os autores, no ethos-estereotipado, os traços exageradamente assinalados levariam à produção de uma imagem/representação-rotulada, que, aliada a outros recursos (linguísticos ou não), muitas vezes, são capazes de gerar comicidade. 
Embora os alicerces teóricos sobre ethos tenham se pautado no discurso verbal (oral ou escrito) manifestado por enunciadores, é possível ampliar o conceito para produções ancoradas também na imagem, como é o caso dos cartuns de $\mathrm{O}$ Amigo da Onça e das charges que associam Michel Temer ao personagem de Péricles. Compostos por partes visual (imagem e cor) e verbal escrita, tais enunciados ajudam a construir o ethos (ou ethos-estereotipado, conforme veremos) das figuras em questão.

O objetivo principal a seguir é, portanto, mostrar que o conceito em foco funciona como fio condutor tanto para aproximar o personagem e 0 expresidente quanto para produzir humor.

\section{O Amigo da Onça, de Péricles Maranhão}

Agir ardilosamente de modo a colocar o outro em situação embaraçosa, e, algumas vezes, perigosa é a principal característica de O Amigo da Onça, personagem que encerra no nome que o intitula seu traço comportamental mais saliente: alguém em quem não se pode confiar. Criado em 1943 por Péricles Maranhão para $O$ Cruzeiro, tornou-se dono de uma das seções de maior sucesso da revista ilustrada mais expressiva do país do século $X X^{5}$. Pelo mesmo motivo, consolidou-se como uma das figuras mais importantes do humor gráfico brasileiro.

Publicadas semanalmente, predominantemente na forma de cartum (espécie de anedota gráfica que tende a ser desenhada em uma cena só), as histórias de Péricles apresentavam um tipo de humor cotidiano, que ressaltava costumes típicos da sociedade e das pessoas da época em que foram produzidas: reiteravam certos comportamentos, criticavam ou desvelavam maneiras de ser. Segundo Jota (1987: 7), Péricles criou mais de mil situações propícias para $\mathrm{O}$ Amigo da Onça sacanear alguém. Para isso, o personagem foi "chefe e subalterno, delegado de polícia e preso, náufrago e comandante, retirante nordestino e gaúcho, criança e adulto".

Independentemente do papel social que assumisse, a composição do tipo físico dele se mantinha a mesma: era baixinho, magro, com cabelo penteado para trás à base de fixador, de bigodinho e olhar cínico. Quando a composição do visual não exigia alguma vestimenta específica, ele apresentava um elegante paletó branco, acompanhado de gravata- borboleta preta, traje que se tornou uma das marcas do personagem.

Péricles afirma ter se inspirado na roupa e no jeito de um garçom que trabalhava no bar onde esboçava suas piadas e desenhos (Bueno 2003: 20).

Veja-se um exemplo dele, com seu tradicional paletó branco:

\footnotetext{
${ }^{5}$ O Cruzeiro constitui um acervo da história do Brasil e de seu jornalismo, sendo responsável pela inovação da imprensa, registrou em suas matérias não apenas o progresso e os acontecimentos que marcaram a trajetória do país, mas também divulgou produtos que ditaram padrões de comportamento e consumo, hábitos de leitura, sintetizando formas de vida (Romancini e Lago 2007).
} 


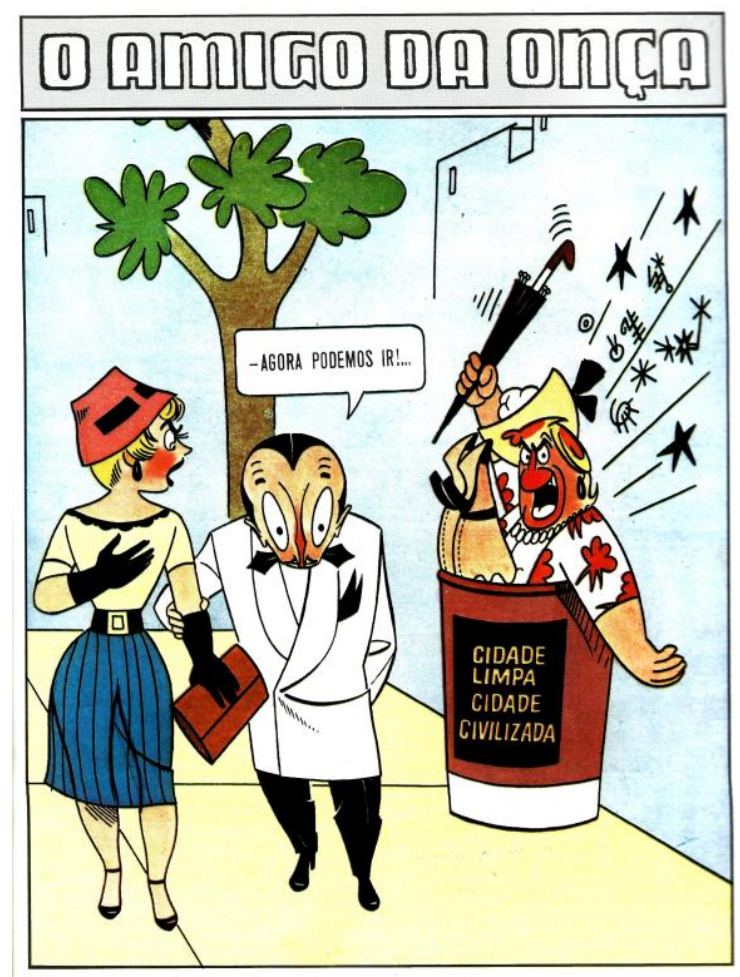

Figura 1: Imagem de O Amigo da Onça, de Péricles Maranhão (Jota 1987: 15)

O nome do personagem associa-se à expressão popular que, no Brasil, diz respeito àquele que se mostra amigo, mas não o é, alguém em quem não se pode confiar e que tende a colocar os outros em situações difíceis (e embaraçosas). Essas são as considerações mais comuns ou recorrentes registradas em alguns dicionários que fazem menção à expressão, como o de Serra e Gurgel (1998). Mas não são as únicas. A construção tem conotações bastante plurais, assumindo outros valores semânticos negativos, como debochado, enganador, irônico, impiedoso, malicioso, irreverente, cafajeste, galhofeiro.

Quanto à raiz do personagem, havia relatos de que teria sido inspirado em Enemigos del Hombre, série de Guillermo Divito e publicada na revista de Dante Quinterno (1909-2003), a Patoruzú, (supunha-se) entre 1936 e meados da década de 1940. Tais considerações constam em registros de Millôr Fernandes (1987) e Paulo Caruso (1990). Procurando atestar a veracidade dessa informação, Carmelino e Flores (2018) demonstram que O Amigo da Onça apresenta vários elementos que o aproximam de Enemigos del Hombre, o que constata que uma série de fato influenciou a outra. A verificação deu-se por meio de pesquisa documental que buscou comparar ambas as séries ${ }^{6}$, levando em conta o contexto de produção (suporte, gênero, formato, linguagem, composição, temas, cenas criadas), as características dos personagens e o tipo de humor (estereótipo mobilizado).

A produção de Péricles com o personagem (de 1943 a 1962) pode ser situada numa "espécie de primavera democrática", caracterizada por "populismo" e "nacional-desenvolvimentismo" (Silva 1989: 22).

\footnotetext{
${ }^{6}$ O estudo analisou precisamente 289 produções de Divito (de 1938 a 1944) e 295 de Péricles (publicadas nos anos de 1943, 1944, 1945, 1952, 1953, 1960 e 1961).
} 
Embora tenha surgido nos anos finais do "Estado Novo"7 (em que houve "entre os desenhistas de humor no Brasil" uma decadência de seu campo de produção, atribuída à violência da censura), o foco de O Amigo da Onça foi reportar situações embaraçosas do cotidiano, não políticas. Como destaca Silva (1989), a menção de Péricles à temática política foi escassa e cautelosa. Dois desenhos apenas se referem explicitamente ao tema:
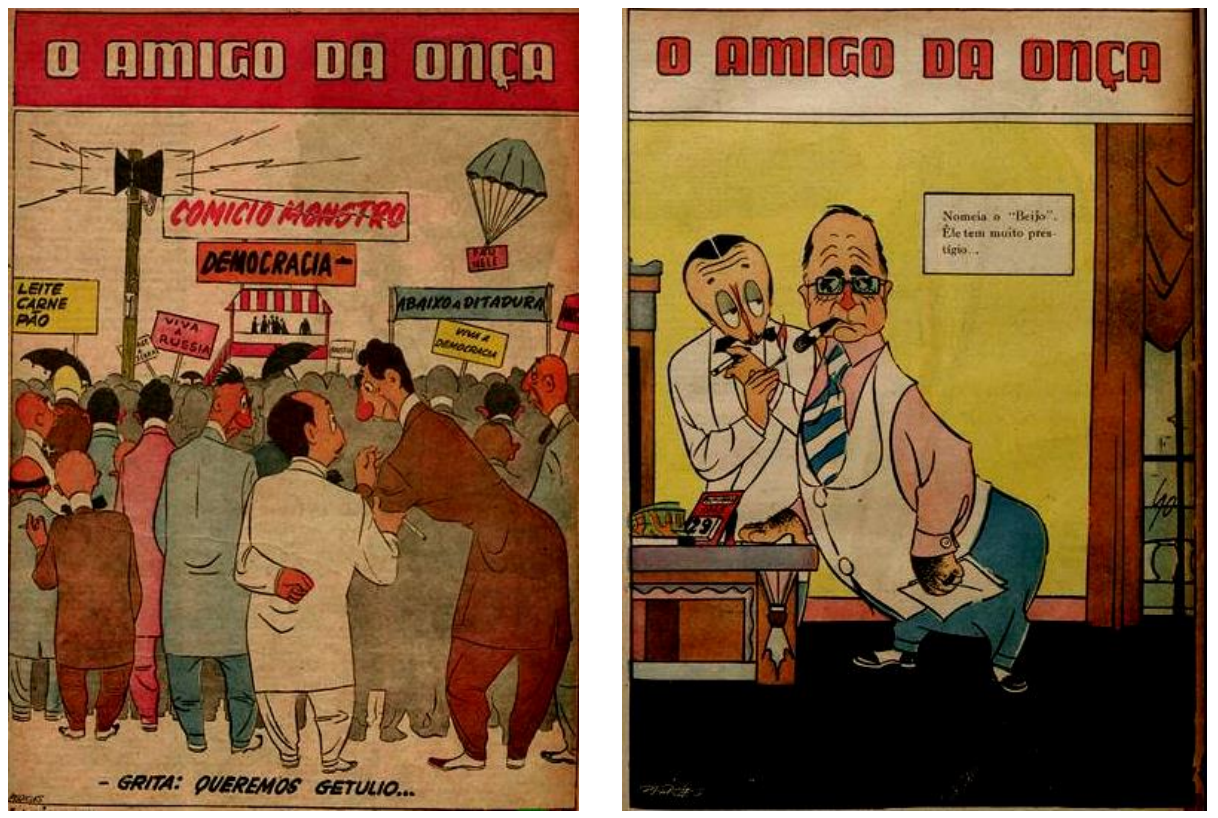

Figuras 2 e 3: Fim do Estado Novo é tema de histórias de O Amigo da Onça (P. Maranhão, O Cruzeiro, 5 mai. 1945: 43; P. Maranhão, O Cruzeiro, 10 dez. 1945: 43)

As duas histórias são de 1945 e se passam no último ano de mandato do então presidente Getúlio Vargas (1882-1954). A Figura 2, publicada em 5 de maio, mostra um "Comício monstro" (como descrito em uma das faixas) contra o político (os demais cartazes traziam "Democracia", "Viva a democracia", "Leite, carne, pão", "Anistia", "Abaixo a ditadura" e "Pau nele"). Na cena, o Amigo da Onça diz: "Grita: queremos Getulio". Ele instava o homem com quem conversava a manifestar apoio, aos gritos, a quem era criticado no protesto.

Na Figura 3, vê-se o personagem acendendo o charuto a Getúlio e o aconselhando: "Nomeia o 'Beijo'. Ele tem prestígio". Trata-se de um conselho sarcástico: o presidente já não ocupava mais o cargo - o desenho foi publicado mais de um mês após seu afastamento, em 29 de outubro de 1945. Conforme Silva (1989: 36), "a produção do personagem construiu a memória de um mundo alheio em permanente crise".

Outras poucas referências à situação política podem ser vistas, porém de forma indireta, nos casos em que O Amigo da Onça coloca aqueles que ocupam algum cargo numa situação embaraçosa ou inusitada, evidenciando o ethos do político (corrupto, sem caráter), como ocorre na Figura 4, em que ele

\footnotetext{
7 Estado Novo teve início no Brasil em novembro de 1937, com um golpe de estado que pôs Getúlio Vargas no poder. Marcado pelo autoritarismo, censura e suspensão de eleições presidenciais, o regime político terminou com a deposição de Vargas em 29 de outubro de 1945 (Skidmore 1982).
} 
recomenda a um vereador agredir um dos homens mostrados na cena ("Rapaz, taca-lhe a mão!") pelo fato de, por ocupar cargo no legislativo, ter direito a imunidade parlamentar ("Você não é vereador? Tem imunidade...").

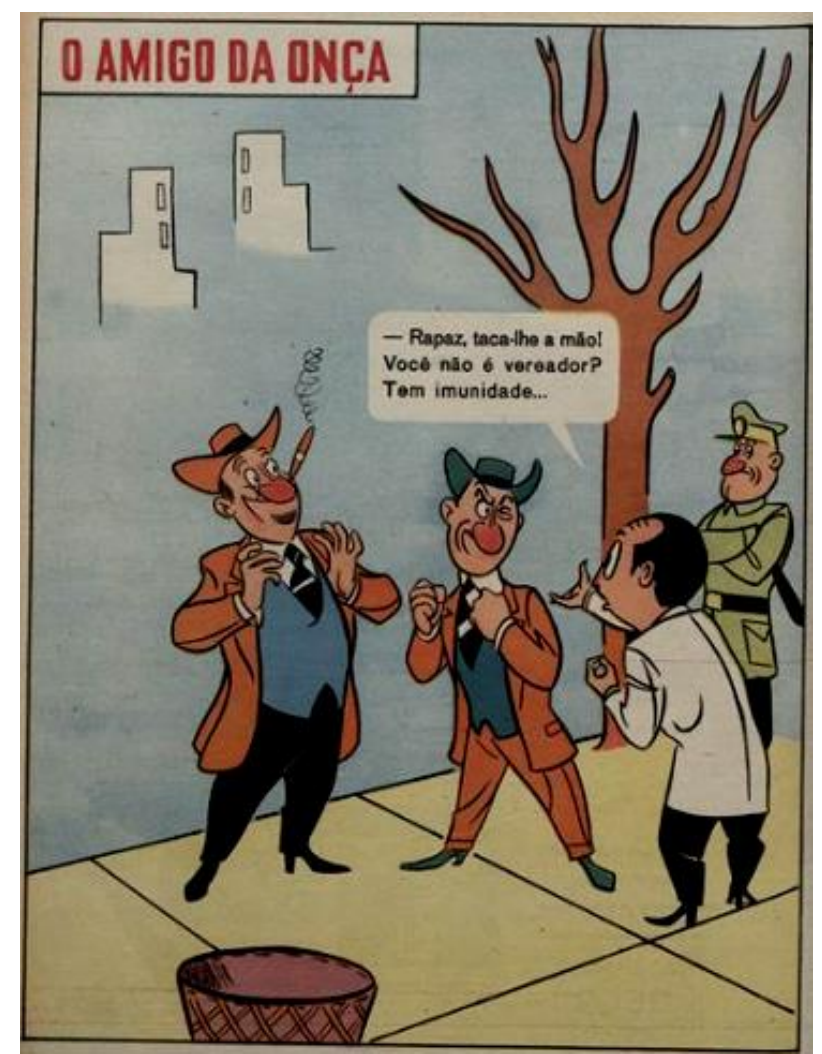

Figura 4: Referência a ethos de políticos em desenho de O Amigo da Onça (Péricles Maranhão, O Cruzeiro, 25 fev. 1961: 90)

Partindo dessas considerações, passemos a observar a aproximação de 0 Amigo da Onça com Michel Temer em charges que circularam na Internet durante os anos de 2015 e 2016.

\section{Michel Temer, o amigo da onça da vez}

Para que se entenda o ethos do ex-presidente do Brasil Michel Temer, associado ao de $\mathrm{O}$ Amigo da Onça, é preciso, inicialmente, que se contextualize $^{8}$ a época em que as charges foram produzidas e circularam, ou seja, a situação política a que elas remetiam. Filiado ao PMDB (Partido do Movimento Democrático Brasileiro), Temer foi reeleito vice-presidente do Brasil nas eleições de 2014 na chapa encabeçada por Dilma Rousseff, do PT (Partido dos Trabalhadores). Ambos tomaram posse em 10 de janeiro do ano seguinte. Foi um pleito acirrado: ela foi eleita com $51,64 \%$ dos votos válidos, o que revelava uma forte divisão política no país.

A oposição começou a fomentar um discurso voltado à desestabilização política do novo governo.

\footnotetext{
${ }^{8}$ A contextualização foi feita a partir de reportagens veiculadas à época. A maior parte delas foi obtida por meio de arquivos digitais do jornal "Folha de S. Paulo", acessados na página virtual "Acervo Folha" (https://acervo.folha.com.br/index.do).
} 
Nos primeiros meses de 2015, já se viam protestos nas ruas e pedidos de impeachment. Em março, a popularidade da presidente atingia $13 \%$ de aceitação (ótimo ou bom), segundo pesquisa do Datafolha, instituto pertencente ao Grupo Folha, do jornal Folha de São Paulo (para 24\% dos entrevistados, a administração era regular e, para $62 \%$, ruim ou péssima).

Esse cenário - somado à situação econômica, pautada por cortes e austeridade fiscal, e a denúncias de corrupção envolvendo seu governo e o de seu antecessor, Luiz Inácio Lula da Silva - perdurou durante aquele ano e contribuiu para a criação de um ambiente propício para a tramitação do afastamento dela do cargo. Em 2 de dezembro, um pedido de impeachment, foi acatado pela presidência da Câmara dos Deputados. O trâmite previa deliberação dos deputados, encaminhamento ao Senado, defesa da presidente e votação - se houvesse maioria entre os senadores, ela seria afastada em definitivo.

O processo se prolongou até agosto de 2016. Em 17 de abril, os deputados federais decidiram autorizar o Senado a implementar o processo de afastamento de Dilma Rousseff pela acusação de crime de responsabilidade fiscal - a administração dela teria usado estratégias de remanejamento de verbas para fechar o orçamento. Em 12 de maio, o Senado aprovou a continuidade do processo. O regimento estipulava o afastamento temporário da presidente enquanto a decisão final não fosse tomada. Michel Temer assumiu o cargo interinamente. Em 31 de agosto, Dilma Rousseff foi formalmente afastada do cargo. Em sua defesa, justificou ter sido vítima de um golpe. Na mesma data, Temer se tornava, agora oficialmente, o 370 presidente da história do Brasil.

O papel de Temer antes da abertura do processo de impeachment sinalizava que ele e seu partido demonstravam interesse pelo cargo presidencial. Em programas eleitorais do PMDB exibidos na televisão em setembro e outubro de 2015, o vice-presidente teve papel de destaque e as falas indicavam um tom crítico à gestão Dilma Rousseff. Essa guinada foi amplamente noticiada pela imprensa. As conjecturas dos analistas políticos eram que o vice procurava se mostrar como uma alternativa viável à presidente.

Em 7 de dezembro, três dias depois do aceite de um dos pedidos de impeachment, Temer redigiu uma carta encaminhada à presidente e que foi reproduzida pela imprensa ${ }^{9}$.

No texto, ele aludia ao "intenso noticiário destes últimos dias" e reiterou lealdade à presidente. Porém, registrou que sempre teve "ciência da absoluta desconfiança da senhora [Dilma Rousseff] e do seu entorno em relação a mim e ao PMDB". Segundo Temer, ele teria tido papel figurativo ("éramos meros acessórios, secundários, subsidiários"), sendo desconsiderado em decisões importantes e acionado somente em episódios pontuais em que ele ou seu partido fossem necessários. O vice encerrou a carta registrando que tinha convicção de que "a senhora não tem confiança em mim e no PMDB, hoje, e não terá amanhã".

\footnotetext{
${ }^{9}$ Sadi (2015), carta disponível em: http://g1.globo.com/politica/noticia/2015/12/leia-integrada-carta-enviada-pelo-vice-michel-temer-dilma.html
} 
Se a percepção dos analistas políticos já dava sinais de que Temer tinha interesse na presidência - algo aludido pelo próprio vice na carta -, não é de estranhar que ela tenha motivado também a interpretação que os chargistas passaram a fazer desse momento político.

A leitura que alguns dos desenhistas fizeram à época era que Temer agia com interesse. Ele demonstrava lealdade, mas indicava ter olhos no cargo presidencial. Agia, portanto, com dissimulação, daí a associação a O Amigo da Onça. Usar o personagem era uma forma de sintetizar a atitude do vice por meio de uma solução verbal (via uso da expressão) e visual (ideia resumida com sua retomada e das atitudes que representa).

Como é próprio do gênero, a charge tem como marca apresentar uma leitura crítica e tendencialmente humorística dos acontecimentos do noticiário com os quais dialoga.

$E$, não custa reforçar, é assinada, ou seja, tem um enunciador explícito que se responsabiliza pelo que enuncia. Trata-se, portanto, de um texto opinativo, que se enquadra no campo do humor e que, por consequência, não pretende ser realista.

Após o impeachment e até o término do mandato de Temer, houve mais de uma situação em que ele foi aproximado a O Amigo da Onça. Coletamos 18 exemplos: 16 se referiam ao momento descrito anteriormente e objeto desta análise; duas o associavam ao personagem, porém em outras situações e, por isso, foram desconsideradas. As 16 produções identificadas circularam em diferentes ambientes digitais e nem sempre nos sites ou redes sociais dos autores que as criaram - é corrente na Internet que os trabalhos sejam replicados pelos leitores.

Por conta disso, para a análise, foram levadas em consideração a página virtual onde a charge foi encontrada e a data de veiculação, informações que serão explicitadas nas legendas delas.

Embora usassem a mesma estratégia para fazer a leitura crítica daquele momento político (vinculação de Temer a O Amigo da Onça), os trabalhos se distinguiam em um aspecto: parte explicitava o vínculo com a criação de Péricles por meio das modalidades verbal (com o uso da expressão que 0 intitula ou por menção ao desenhista de O Cruzeiro) e visual, outra parte somente com imagens, sem apoio da parte verbal.

Por conta disso, buscamos dividi-las em duas categorias, considerando que a associação do político com o personagem mobiliza: a) memória visual e b) memória verbal e visual. Nas análises, abordaremos quatro exemplos, recorte necessário por questões de espaço e para evitar redundâncias.

\section{a) memória visual}




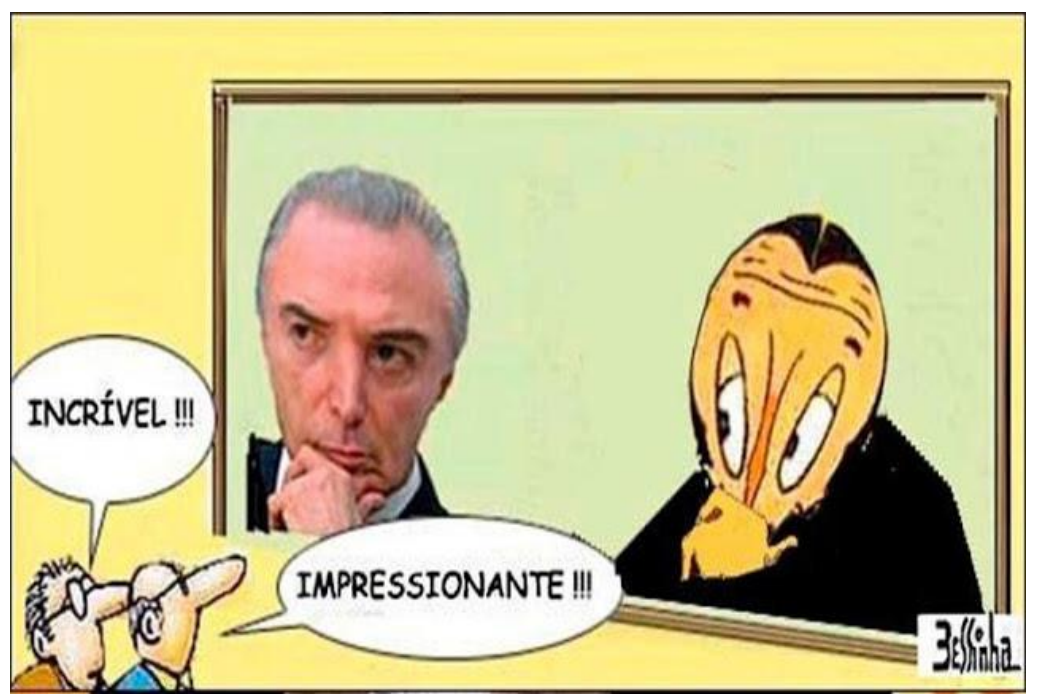

Figura 5: Charge de Bessinha (Bessinha 8 dez. 2015)

A charge é do cartunista Bessinha (Roberto Bessa) e foi reproduzida por um leitor no espaço dos comentários do site noticioso Jornal GGN, cujo posicionamento editorial era bastante crítico a Michel Temer. O leitor se manifestava a respeito de um texto, intitulado "Breves considerações sobre a incrível carta de Temer" e veiculado um dia depois de o então vice-presidente redigir seu ponto de vista a Dilma Rousseff (a carta foi assinada em 7 de dezembro de 2015). Segundo o leitor, o "personagem atual só preencheu a moldura que já estava criada por Péricles".

Construída sob a cenografia ${ }^{10}$ de uma exposição de pinturas, a charge mostra um quadro sendo observado por duas pessoas, que se espantam com o que veem (os enunciados verbais "incrível" e "impressionante" confirmam o estado de espanto): uma foto de Temer (imagem à esquerda do quadro) ao lado de O Amigo da Onça (à direita).

Ambos são mostrados com a mesma pose: olhos voltados para o lado e mãos segurando o queixo (como se estivessem pensando). O que surpreende a quem aprecia aquela obra de arte, além da pose idêntica, é a semelhança fisionômica entre as duas figuras retratadas, como se um refletisse o outro. Tal construção sugere uma aproximação/identificação entre eles. Nesse sentido, Temer é associado visualmente a O Amigo da Onça. O mesmo acontece, de forma ainda mais contundente, na charge da Figura 6.

\footnotetext{
${ }^{10} \mathrm{Na}$ terminologia de Maingueneau (2005), o processo comunicativo, tido como a cena de enunciação, organiza-se interiormente em três dimensões: cena genérica (refere-se ao gênero de discurso a que pertence a atividade social), cena englobante (diz respeito ao tipo de discurso, campo a que pertence a atividade social caracterizável) e cenografia (instituída pelo próprio discurso, consiste na forma como o quadro cênico é apresentado, enquadrado; o modo como o enunciador organiza a situação em que enuncia).
} 

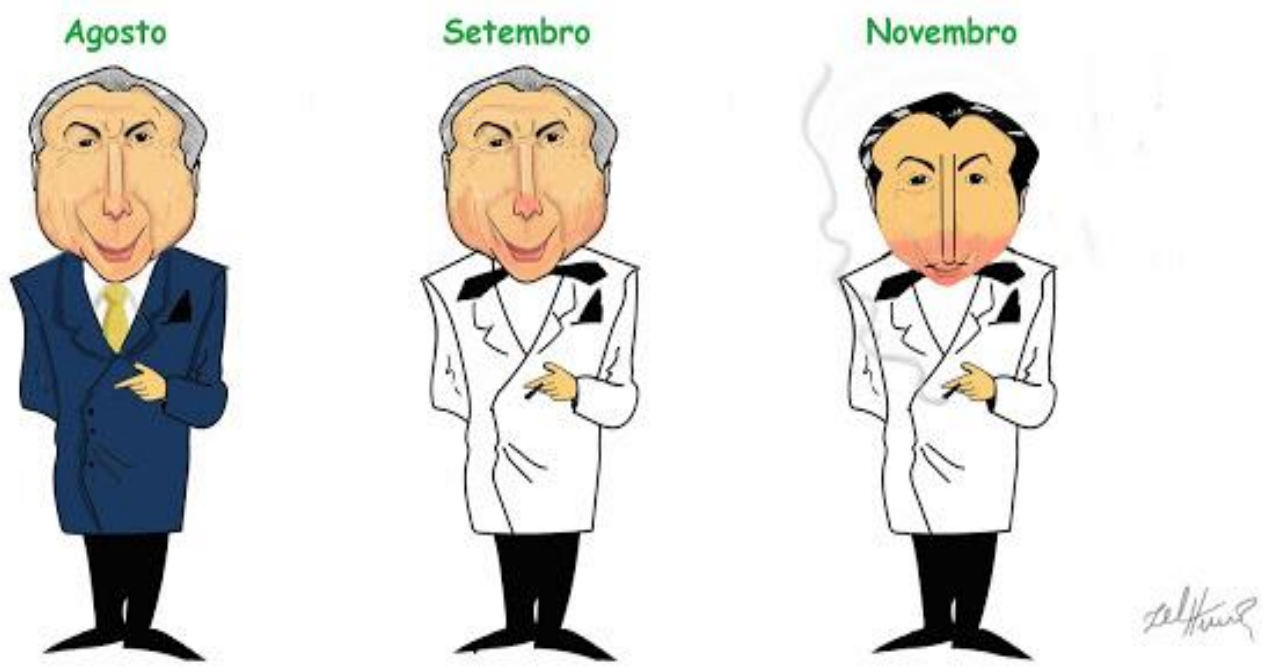

Figura 6: Charge de Zel Humor (Zel Humor 8 dez. 2016)

Criada pelo desenhista Zel Humor e veiculada no site do autor em 8 de dezembro de 2016, a charge procura mostrar que Temer foi se transformando, entre agosto e novembro daquele ano, na figura de O Amigo da Onça.

O período corresponde ao início oficial de seu mandato presidencial depois de assumir o cargo interinamente em 12 de maio, ele foi empossado 31 de agosto após a finalização do processo de impeachment. Na leitura proposta pelo desenhista, a passagem oficial de vice a presidente ajudou a confirmar uma atitude não confiável de Temer. O que explicita isso é justamente a vinculação dele à criação de Péricles. Note-se que a primeira associação é por meio do vestuário, o tradicional paletó branco. Na sequência, o rosto também é modificado, assumindo, formalmente, a feição do personagem da revista $O$ Cruzeiro.

Considerando-se as duas charges, observa-se que o ethos que os enunciadores constroem para Temer espelha-se na memória da representação de $O$ Amigo da Onça. Desse modo, toda a construção pensada para o personagem nas histórias - aquele que age como gozador, trocista, maldoso, irônico, malandro, perverso, desleal, falso, vingativo e mau-caráter -, que pode ser resumida em um ethos mais geral (e estereotipado) de sacana, tende a ser transposta ao então presidente. Essa imagem discursiva é garantida, nos dois exemplos, por índices imagéticos que se fazem presentes na materialidade do texto.

Na Figura 5, a aparência física (considerando-se a face especificamente) e a pose de Temer são assemelhadas à de $O$ Amigo da Onça, com o qual é posto em comparação explícita (um ao lado do outro). O tom dessa enunciação é de espanto, dado visto, como já comentado, a partir dos enunciados verbais proferidos ("incrível" e "impressionante"), que revelam surpresa na similaridade.

Já na Figura 6, Temer vai se transformando ao longo de meses (aspecto observado nas imagens sequentes, que correspondem à mutação de Temer nos meses de agosto, setembro e novembro) na imagem idêntica (corpo, modo de se vestir, pose e face) do personagem criado por Péricles.

Trata-se da construção de um ethos-estereotipado (nos termos de Carmelino e Gatti 2018), no qual os traços demasiadamente assinalados 
(formato e tipo de cabelo, sobrancelha, nariz e indumentária) são capazes de gerar comicidade. O tom da enunciação é de evidência, uma vez que se busca simplesmente demonstrar a identificação.

\section{b) memória verbal e visual}

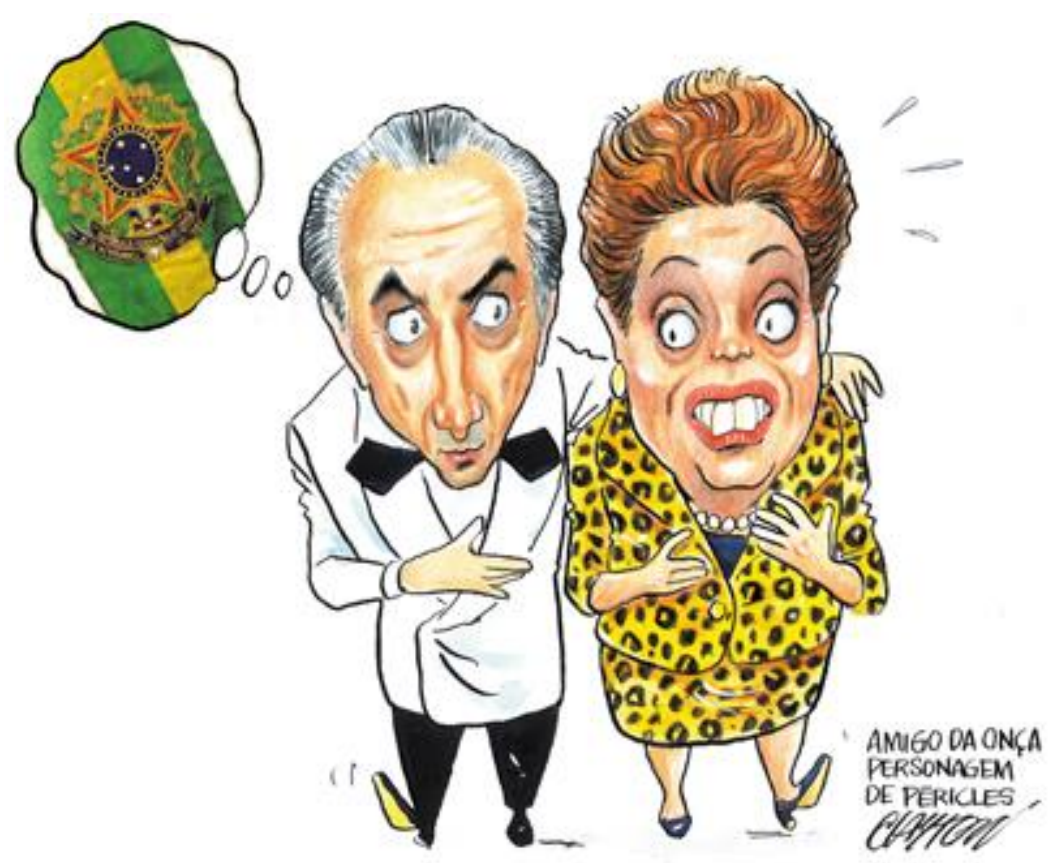

A senhora precisa confiar em mim e no PMDB!

Figura 7: Charge de Clayton (Clayton 9 dez. 2015)

A charge reproduzida na Figura 7 circulou no "Blog do Eliomar", mantido de $O$ Povo, jornal onde o autor do desenho, Clayton, mantém uma seção fixa. A data de veiculação dela - 9 de dezembro de 2015 - alude, uma vez mais, à carta apresentada por Temer a Dilma dois dias antes. Trata-se, portanto, de outro desenhista a se valer desse fato para vincular o então vice-presidente a O Amigo da Onça - no caso, a expressão fica ainda mais evidenciada pelo fato de a coloração da roupa usada por Dilma ser próxima à de uma onça, tornando-a uma metáfora visual do animal.

Enquanto externamente o vice demonstra amizade, pondo a mão no ombro da colega e afirmando apoio a ela e também de seu partido (como se lê na legenda: "A senhora precisa confiar em mim e no PMDB!"), internamente revela estar mesmo é interessado no cargo dela (informação depreendida pela faixa presidencial mostrada no balão de pensamento que revela seu verdadeiro desejo). Ocorre situação semelhante neste outro exemplo: 


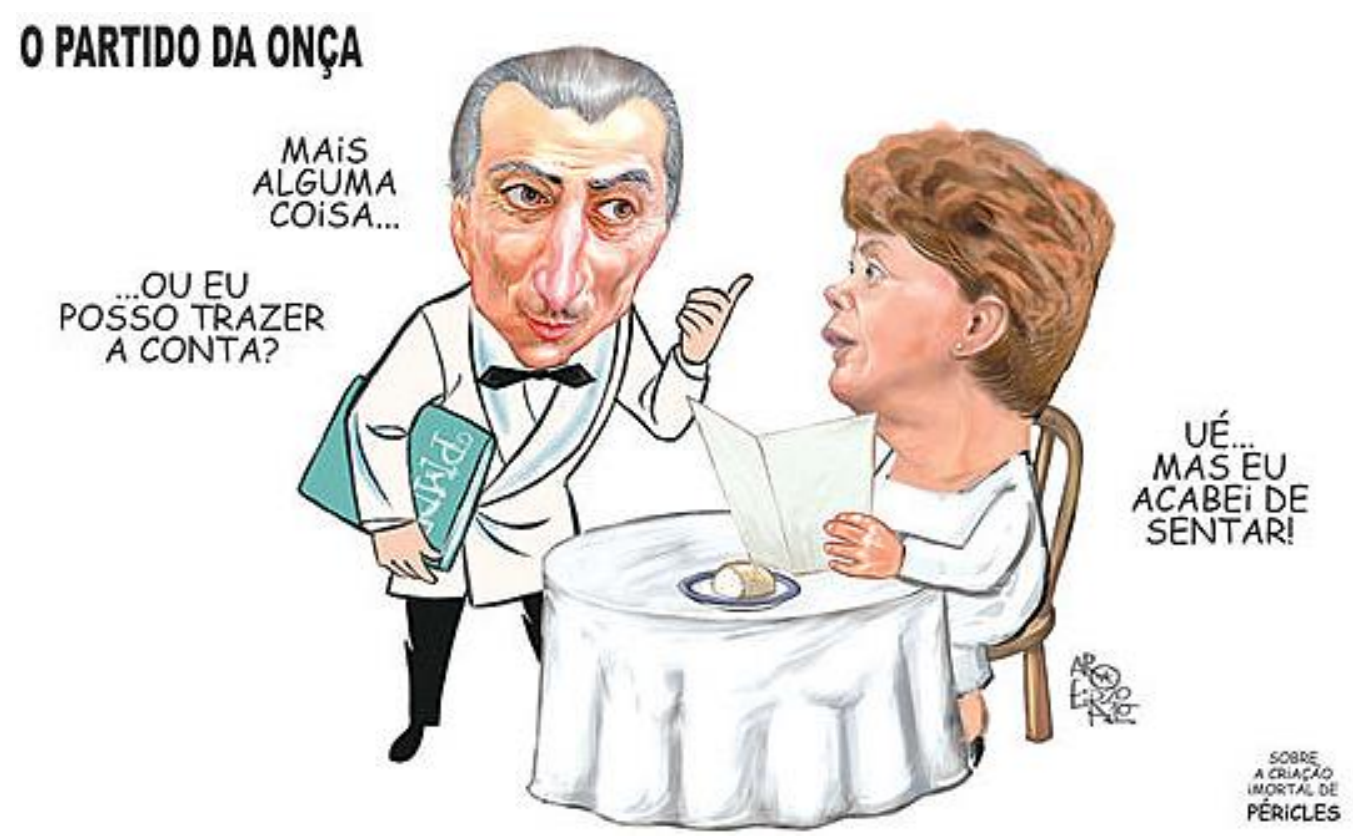

Figura 8: Charge de Aroeira (Aroeira 30 ago. 2016)

A figura 8 foi exposta em 30 de agosto de 2016 no já mencionado site Jornal GGN e é assinada por Renato Aroeira (2016) - ele registra apenas o sobrenome nas produções que faz. A charge ilustrava um artigo intitulado "Golpe" e procurava rotular Temer a um golpista. A data de veiculação era bastante representativa: a véspera da votação final do processo de impeachment no Senado. Produzida sob a cenografia de refeição em restaurante, ela mescla imagética e verbalmente Temer a duas figuras: à de um garçom (cardápio na mão, oferta de "mais alguma coisa" ou se já poderia "trazer a conta") e à de O Amigo da Onça (paletó branco, título da charge "PARTIDO DA ONÇA" e a nota abaixo do canto direito da charge, que diz "Sobre a criação imortal de Péricles"). Essa junção não deveria estranhar, posto que, como já comentado, Péricles afirmava ter se baseado em um garçom para compor o visual de seu personagem. Tomando como base as duas últimas produções humorísticas (figuras 7 e 8 ), verifica-se que o ethos construído para Temer pelos enunciadores também é refletido na figura de 0 Amigo da Onça. Tal representação discursiva, em ambos os casos, é garantida tanto por índices linguísticos quanto imagéticos, que estão presentes na materialidade do texto.

Na charge da Figura 7, observa-se que a aproximação de Temer à criação de Péricles pode ser vista imageticamente (ressaltam-se a semelhança física e o modo de se vestir: feição e uso de paletó branco), bem como por elementos linguísticos (a nota abaixo do canto direito da charge, que diz "Sobre a criação imortal de Péricles") e atitudinais (a ironia peculiar: dizer uma coisa, mas pensar em fazer outra).

O tom da enunciação é, ao mesmo tempo, de dissimulação - o que se observa a partir do comportamento irônico de Temer/O Amigo da Onça, que diz e faz algo (num ato de abraço de "amigo", pede a Dilma que confie nele e em seu partido), enquanto pensa em outra coisa (assumir o cargo dela, como visto por meio da presença da faixa presidencial) - e de constrangimento 
(depreendido pela feição de Dilma, que se mostra desconfortável com a situação, tanto pelo pedido quanto pelo abraço).

No caso da Figura 8, como comentado, a produção é apresentada sob a cenografia de uma refeição em restaurante. Nela, há uma aproximação da figura de Temer a O Amigo da Onça, notada imageticamente (ressaltam-se a semelhança física e o modo de se vestir: feição e uso de paletó branco), bem como por elementos linguísticos (o enunciado verbal em caixa alta que corresponde à legenda da charge "PARTIDO DA ONÇA" e a nota abaixo do canto direito da charge que diz "Sobre a criação imortal de Péricles"). O tom de enunciação é de impaciência por parte de Temer (revelado pelas indagações "Mais alguma coisa..." e "... ou posso trazer a conta?") e de surpresa de Dilma (observada pelo enunciado verbal que responde às indagações: "Ué... mas eu acabei de sentar!").

A cenografia do restaurante funciona como metáfora para a situação vivida no país na época: a pressa para que a Dilma peça a conta antes de ter feito seu pedido sugere a pressa de Temer para que ela deixe o cargo de presidente antes mesmo de o processo de impeachment ser oficialmente finalizado (o que ocorreu no dia seguinte à data veiculação da charge). Daí a possibilidade de o ethos, também nesse caso, associar as figuras no que se refere ao comportamento sacana.

O humor crítico presente nas quatro produções gráficas, ou seja, a quebra de expectativa na narrativa (uma das marcas do gênero charge), deve-se à aproximação, ou melhor, à identificação de Temer a O Amigo da Onça e ao que essa atitude representa: a "brincadeira" proposta pelos enunciadores é transpor o ethos de um ao outro. Além dessa estratégia discursiva, por se tratar de produção vinculada ao campo do humor, outros mecanismos poderiam ser apontados. Na teoria do riso, há em Freud (1977) a descrição de uma técnica de produção de humor que funciona a partir da remissão mnemônica de implícitos, chamada por ele de "chiste por alusão". Essa técnica alia-se, segundo entendemos, à que propomos para explicar os casos analisados, a de transposição de ethos. Conforme Freud (1977: 93), trata-se "da questão de representar alguma coisa, que não pode ser expressa diretamente".

A técnica consiste na representação indireta de um elemento através de sua sugestão conceitual em outro: "é a substituição por algo que lhe seja vinculado em uma conexão conceptual" (Freud 1977: 94). O sucesso, por assim dizer, do chiste cabe à habilidade de inferência e à possibilidade de reconhecimento do leitor. No caso das charges analisadas, entendemos que, partindo do ethos de $\mathrm{O}$ Amigo da Onça, é possível reconstruir, por meio da associação e da inferência imagética, o ethos de Temer. A alusão é tida como chiste quando busca representar "as coisas" ou "conceitos" de alguma maneira anteriormente interdita ou que, pelo menos, seja incomum, daí a quebra de expectativa. Para sugerir que Temer seja falso, uma pessoa não confiável, os enunciadores fazem isso por meio de uma conhecida figura do humor gráfico brasileiro.

Como se observa, nas charges das figuras 5 e 6 não há menção verbal ao personagem de Péricles, apenas visual, dado que exige uma memória maior do 
leitor a respeito de quem Temer está refletindo (Figura 5) ou em quem está se transformando (Figura 6).

No caso das charges das figuras 7 e 8 , a menção a 0 Amigo da Onça pode ser explicitamente observada a partir das legendas que se encontram abaixo, na lateral do canto direito do desenho: "Amigo da Onça - personagem de Péricles" (Figura 7) e "sobre a criação imortal de Péricles" (Figura 8).

Recuperando a proposta de Courtine (2009) sobre memória discursiva cuja especificidade está na detecção de traços memoriais (repetição, esquecimento, reformulação) na materialidade discursiva -, verifica-se que as charges são formulações que retomam e repetem discursos. O discurso que as produções humorísticas veiculam é o da falsidade, em todos os casos, tendo em vista que o ethos do personagem sacana, aquele em que não se pode confiar, porque sempre apronta, é transposto para o ex-presidente brasileiro, de forma explícita (seja pela imagem ou menção a expressão verbal).

Embora saibamos (não custa reforçar, uma vez mais) que as charges são produções humorísticas que não pretendem ser realistas, diante do exposto fica uma questão: em que se baseiam os enunciadores das charges para (re)produzirem o ethos de Temer associando-o ao de O Amigo da Onça? Uma pesquisa de avaliação do governo feita pelo instituto Datafolha em 11 de dezembro de 2016 revela que o "brasileiro vê Temer como falso, desonesto e protetor dos ricos", como se nota neste trecho:

Segundo pesquisa Datafolha divulgada neste domingo 11 , a população considera Michel Temer falso $(65 \%)$, muito inteligente $(63 \%)$ e defensor dos mais ricos $(75 \%)$; metade dos brasileiros veem Temer como autoritário e $58 \%$, desonesto; de zero a dez, a nota média dada ao desempenho do governo Michel Temer é 3,6 (Brasil 247, 11 dez. 2016). ${ }^{11}$

Desse modo, podemos considerar que os chargistas (enunciadores responsáveis pelo que enunciam em suas produções gráficas) podem ter se baseado na imagem que o público já tinha/tem de Temer, criando expectativas sobre o ex-presidente, mas tendo como base seu posicionamento ideológico e o gênero discursivo que produzem.

\section{Considerações Finais}

No texto chárgico, a memória discursiva tem papel essencial: as produções se efetuam em certas condições de uma conjuntura movimentando formulações anteriores, já enunciadas. Nos casos analisados, foi possível observar que os enunciados retomados repetem efeitos de memória específicos: a aproximação de 0 Amigo da Onça, personagem criado por Péricles Maranhão no século passado para a revista $O$ Cruzeiro, a Michel Temer, vice-presidente do Brasil que assumiu o cargo após o impeachment de Dilma Rousseff, faz repetir na memória não apenas a figura física, mas também suas características.

11 Disponível em: https://www.brasil247.com/brasil/brasileiro-ve-temer-como-falsodesonesto-e-protetor-dos-ricos 
A associação entre as personalidades (a de Temer com a do personagem de Péricles), nos quatro exemplos, exige do leitor uma memória discursiva.

Como dito na introdução deste texto, para entender as charges é preciso recuperar os enunciados e/ou fatos que motivaram sua criação, pois, sem essas informações, é difícil saber qual o seu tema e esclarecer como o riso é suscitado. No caso em tela, foi a atitude/postura de Temer, pouco confiável, que fez com que os enunciadores 0 aproximassem de uma figura historicamente conhecida no humor gráfico brasileiro como sendo "aquele em quem não se pode confiar".

A memória - do aspecto físico de O Amigo da Onça, do nome dado a ele e das atitudes que caracterizam o personagem - é essencial para o empreendimento discursivo das charges. Trata-se da recuperação de uma memória social não apenas de figura icônica de Péricles, mas também de acontecimentos exteriores e anteriores aos textos das charges que refletem materialidades que intervêm em sua construção.

E é diante desse quadro que se manifesta o ethos, conceito teórico central utilizado nesta discussão. Os enunciadores - os chargistas - trabalharam com a premissa da existência de elementos inerentes a O Amigo da Onça e que foram retomadas à medida que o próprio personagem era resgatado: o de ser uma pessoa pouco confiável, que procura sempre colocar o outro em situações embaraçosas, vexatórias, inusitadas. Tais elementos foram evocados na materialidade do texto tanto visualmente (nos exemplos apoiados apenas na imagem dele, como visto nas figuras 5 e 6) ou articulando as partes imagética e verbal (figuras 7 e 8 ).

Diante da hipótese trabalhada neste texto, a de que esse ethos de pouco confiável pode ser vinculado a outras pessoas com a finalidade de produzir crítica e humor, verificou-se, por meio das análises, que isso fica evidente nos exemplos relacionados a Michel Temer. $\mathrm{E}$ pode ser retomado a outras figuras também, a depender da situação e do interesse do enunciador. Independentemente de quem venha a ser relacionado com o personagem, 0 (re)uso de O Amigo da Onça acaba tendo como consequência prática sua perpetuação tantos anos depois do encerramento de suas histórias.

\section{Referências bibliográficas}

Acervo Folha. [em linha] Disponível em: https://acervo.folha.com.br/index.do Amossy, Ruty. 2005. O ethos na intersecção das disciplinas: retórica, pragmática, sociologia dos campos, em R. Amossy, Imagens de si no discurso: a construção do ethos, São Paulo, Contexto: 119-144.

Aristóteles. Retórica. (Trad. de M. A. Júnior, P. F. Alberto e A. N. Pena, 2015), São Paulo, Folha de São Paulo.

Aroeira, Renato. 2016. [em linha] Disponível em: https://jornalggn.com.br/noticia/fora-de-pauta-1076

Bessinha. 2015. [em linha] Disponível em: https://jornalggn.com.br/analise/breves-consideracoes-sobre-a-incrivelcarta-de-temer 
Bourdieu, Pierre. 2004. Os usos sociais da ciência: por uma sociologia clínica do campo científico. (Trad. de D. B. Catani), São Paulo, Editora da UNESP.

Brasil 247. 2016. [em linha] Disponível em: https://www.brasil247.com/brasil/brasileiro-ve-temer-como-falsodesonesto-e-protetor-dos-ricos

Bueno, Mário. 2003. A origem curiosa das palavras, Rio de Janeiro, José Olympio.

Carmelino, Ana Cristina. 2009. O texto humorístico: construção de sentido, em L. Vidon e M. P. P. Lins, Da análise descritiva aos estudos da linguagem: a linguística no Espírito Santo, Vitória, PPGEL: 105-122.

Carmelino, Ana Cristina. 2017. A retórica da ironia em O amigo da Onça, EID\&A - Revista Eletrônica de Estudos Integrados em Discurso e Argumentação, 1: 19-34.

Carmelino, Ana Cristina e Márcio Antonio Gatti. 2018. Leia, ria e curta: o ethos-estereotipado de Dilma Rousseff no Facebook, Revista (Con)Textos Linguísticos, 12, 21: 8-27.

Carmelino, Ana Cristina e Ana Beatriz Flores. 2018. Imprensa e humor gráfico: em questão a origem de O Amigo da Onça, Galáxia, 38 São Paulo [online/: 56-70 Disponivel em: https://www.scielo.br/pdf/gal/n38/1519311X-gal-38-0056.pdf

Clayton. 2015.2 [em linha] Disponível em: http://portaleliomar.opovo.com.br/wp-content/uploads/2015/12/clayton151209.jpg

Courtine, Jean-Jacques. 2009. Análise do Discurso Político: o discurso comunista endereçado aos cristãos (1981). (Tard. De P. Reuillard) São Carlos, Edufscar.

Caruso, Paulo. 1990. Ninguém é de ferro (muito menos a cortina), I Encontro Latino-Americano de humor Brasil-Argentina, São Paulo, Memorial da América Latina.

Fernandes, Millôr. 1987. Péricles, em Péricles, O Amigo da Onça, São Paulo, Busca Vida: 3-4.

Ferreira, Aurélio Buarque de Holanda. 1999. Novo Aurélio Século XXI: o dicionário da língua portuguesa, Rio de Janeiro, Nova Fronteira.

Freud, Sigmund. 1977. Os chistes e sua relação com o inconsciente. (Trad. de J. Salomão), Rio de Janeiro, Imago Editora.

Jota. 1987. Biografia: duas Figuras muito ligadas, em O Amigo da Onça: a obra imortal de Péricles, Rio de Janeiro, Busca Vida Ltda.

Maingueneau, Dominique. 1998. Termos-chave da análise do discurso. (Trad. de M. V. Barbosa, M. E. A. T. Lima), Belo Horizonte, Editora da UFMG.

Maingueneau, Dominique. 2005. O discurso literário, São Paulo, Contexto.

Maingueneau, Dominique. 2008a. A propósito do ethos, em A. R. Mota e L. Salgado (orgs.), Ethos discursivo, São Paulo, Contexto: 11-29.

Maingueneau, Dominique. 2008b. Problemas de ethos, em S. Possenti e M. C. P. Souza-e-Silva (orgs.), Cenas da enunciação, São Paulo, Parábola: 5573.

Maranhão, Péricles. 1945. O Amigo da Onça, O Cruzeiro, 5 de maio, n. 28: 43. Maranhão, Péricles. 1945. O Amigo da Onça, O Cruzeiro, 10. dez, n. 6: 43. Maranhão, Péricles. 1961. O Amigo da Onça, O Cruzeiro, 25 fev., n. 20: 90. 
Pêcheux, Michel. 1999. O papel da memória, em P. Achard et al, O papel da memória, Campinas, Pontes.

Possenti, Sírio. 2014. O humor é um campo, em Cinco ensaios sobre humor e análise do discurso, São Paulo, Parábola Editorial: 11- 40.

Possenti, Sírio e Ana Cristina Carmelino. 2016. Copa 2014 no Brasil: a logomarca virou piada, em L. Aranda e T. L. Vieira (orgs.), Os sentidos do humor: possibilidades de análise do cômico, São Paulo, Verona: 117-133.

Romancini, Richard e Cláudia Lago. 2007. História do jornalismo no Brasil, Florianópolis, Insular.

Sadi, Andréia. 2015. Leia a íntegra da carta enviada pelo vice Michel Temer a Dilma. [em linha] Disponível em:

http://g1.globo.com/politica/noticia/2015/12/leia-integra-da-cartaenviada-pelo-vice-michel-temer-dilma.html

Serra e Gurgel, João Bosco. 1998. Dicionário de gíria: modismo linguístico - o equipamento falado do brasileiro, Brasília, Gráfica Valci Editora LTDA.

Silva, Marcos Antonio da. 1989. Prazer e poder do Amigo da Onça, Rio de Janeiro, Paz e Terra.

Skidmore, Thomas. 1982. Brasil: de Getúlio Vargas a Castelo Branco (1930 1964), (Trad. de I. T. Dantas), Rio de Janeiro, Paz e Terra.

Teixeira, Luiz Guilherme Sodré. 2005. Sentidos do humor, trapaças da razão: a charge, Rio de Janeiro, Fundação Casa de Rui Barbosa.

Zel Humor. 2016. [em linha] Disponível em: http://zelhumortotal.blogspot.com/2016/12/michel-temer-nao-e-amigonem-da-onca.html

NOTA:

A autoria foi dividida de forma equânime entre os dois autores, atendendo a cinquenta por cento de escrita para cada um. 